\title{
Subclinical Nasal and Lung Lymphocytosis in Ulcerative Colitis
}

\author{
Maurizio Marvisi ${ }^{a} \quad$ Laura Balzarini ${ }^{a} \quad$ Chiara Mancini ${ }^{a} \quad$ Sara Ramponi ${ }^{a}$

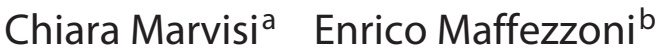 \\ aDepartment of Internal Medicine, Istituto Figlie di San Camillo, Cremona, Italy; \\ ${ }^{b}$ Department of Otolaryngology and General Surgery, Istituto Figlie di San Camillo, Cremona, Italy
}

\section{Keywords}

Extraintestinal manifestations · Inflammatory bowel

disease - Lymphocytes · Lung involvement · Nasal

involvement . Ulcerative colitis

\begin{abstract}
Background: Extraintestinal manifestations are common in ulcerative colitis (UC). Data regarding pulmonary and nasal mucosa involvement are sparse. Objectives: The aim of the study was to evaluate, by using induced sputum (IS) and nasal cytology (NC), the cytological pattern of the lung and nose in patients with UC. Materials and Methods: We enrolled 15 consecutive subjects from the outpatient department with a recent diagnosis of UC. On the same day of enrollment, we performed a global spirometry, including a lung diffusing capacity test, IS analysis, and evaluation of NC. Results: IS analysis showed an increase in lymphocytes in UC patients when compared to those of controls ( $2.8 \pm 0.9$ vs. $0.2 \pm 0.4 \% ; p<0.01)$. NC showed a similar increase in lymphocytes $(12.5 \pm 5.30$ vs. $3.5 \pm 4.0 \% ; p<0.01)$. We found a positive correlation between lymphocyte counts in IS and NC ( $r=$ $0.775 ; p<0.001$ ) and between lymphocytes in IS and NC and grade of intestinal inflammation $(r=0.603, p=0.015 ; r=0.60$, $p=0.013$ ). Conclusions: Our data demonstrated that UC patients may have a subclinical nasal and lung lymphocytosis.
\end{abstract}

(c) 2019 S. Karger AG, Basel

\section{KARGER}

() 2019 S. Karger AG, Basel

E-Mail karger@karger.com

www.karger.com/iid

\section{Introduction}

Extraintestinal manifestations commonly occur in inflammatory bowel disease (IBD). The most common are erythema nodosum, pyoderma gangrenosum, arthritis, uveitis, episcleritis, mouth ulcers, renal stones, thromboembolic disease, and primary sclerosing cholangitis [1].

Respiratory manifestations of IBD have been studied in the literature by small-size case-control studies, case reports, and epidemiological population-based studies concerning both ulcerative colitis (UC) and Crohn's disease. The exact incidence and prevalence of pulmonary involvement in IBD is not known; however, airway involvement constitutes a large proportion, responsible for $40-63 \%$ of overall respiratory incidents [2]. Pulmonary function test abnormalities are found frequently in patients with IBD without the presence of any respiratory symptoms and lung radiograph findings. IBD patients show significantly decreased lung function test outcomes in comparison to healthy controls. In a review including over 600 patients with UC, more than $50 \%$ of patients showed abnormal pulmonary function test results when compared to healthy controls, and the decrease in diffusion capacity of the lung for carbon monoxide (DLCO) was the most common defect $[3,4]$.

We think that highlighting respiratory involvement gives us valuable information about the systemic impact 
Table 1. Histological assessment of mucosal biopsy specimens

\begin{tabular}{ll}
\hline Specimen & Grade \\
\hline Enterocytes & \\
$\quad$ Normal & 0 \\
$\quad$ Loss of single cell & 1 \\
$\quad$ Loss of groups of cells & 2 \\
$\quad$ Frank ulceration & 3 \\
Crypts & \\
$\quad$ Normal & 0 \\
$\quad$ Single inflammatory cell & 1 \\
$\quad$ Cryptitis & 2 \\
$\quad$ Crypt abscesses & 3 \\
Lamina propria mononuclear cells & 0 \\
$\quad$ Normal & 1 \\
$\quad$ Mild increase & 2 \\
Moderate increase & 3 \\
Marked increased & \\
Neutrophils & 0 \\
$\quad$ Normal & 1 \\
Mild increase & 2 \\
Moderate increased & 3 \\
Marked increased &
\end{tabular}

Conversion of histological scores to grades was carried out according to the following: grade (total score): $0(0-1) ; 1(2-4) ; 2$ (5-8); 3 (8-10); 4 (10-12).

of the disease. Moreover, knowing the cytological pattern of nasal and lung involvement in UC can help otorhinolaryngologists and pulmonologists in differential diagnosis. Pulmonary involvement in IBD is often asymptomatic and detectable only at the time of lung function investigation. On the other hand, data regarding subclinical nasal mucosa involvement are sparse.

The aim of the study is to evaluate, by using induced sputum and nasal cytology, the cytological pattern of the lung and nose in UC patients without pulmonary and nasal symptoms.

\section{Materials and Methods}

We enrolled 15 consecutive patients from the outpatient department of gastroenterology with a recent diagnosis of active UC. The diagnosis was based on clinical and morphological data. Multiple mucosal biopsy specimens were taken from macroscopically affected regions during colonscopic assessment. All subjects were nonsmokers and had a negative history for asthma and rhinitis.

They did not take steroids or other anti-inflammatory drugs. On the same day, all patients underwent a colonoscopy, a blood sample to evaluate ERS, CRP, ANCA, hemochrome, a global spi-
Table 2. Spirometric and cytological data

\begin{tabular}{lccl}
\hline & $\begin{array}{l}\text { UC patients } \\
(n=15)\end{array}$ & $\begin{array}{l}\text { Control subjects } \\
(n=15)\end{array}$ & $p$ value \\
\hline Sex, male/female & $6 / 9$ & $7 / 8$ & $\mathrm{~ns}$ \\
Age, years & $60 \pm 13$ & $57 \pm 10$ & $\mathrm{~ns}$ \\
FVC pred. & $87.67 \pm 14.74$ & $95.33 \pm 12.17$ & 0.132 \\
DLCO & $80.47 \pm 17.46$ & $92.27 \pm 9.8$ & 0.030 \\
DLCO/VA & $80.01 \pm 14.31$ & $91.54 \pm 10$ & 0.016 \\
Lymp N & $12.5 \pm 5.3$ & $3.5 \pm 4.0$ & $<0.001$ \\
Lymp IS & $2.8 \pm 0.9$ & $0.2 \pm 0.4$ & $<0.01$ \\
\hline
\end{tabular}

FVC, forced vital capacity; DLCO, diffusion capacity for carbon moxide; VA, alveolar volume; Lymp N, lymphocytes in nasal tissue; Lymp IS, lymphocytes in induced sputum.

rometry including DLCO, skin prick tests, and induced sputum and evaluation of nasal cytology. Each biopsy specimen was assessed blindly by one histopathologist with a special interest in gastrointestinal diseases, who was unaware of the disease activity index of each case. In each specimen, scores were assigned to the severity of surface enterocyte damage, cryptitis, and acute and chronic inflammation in the lamina propria (Table 1).

The control group consisted of 15 healthy nonsmoking subjects matched for age and sex. All patients gave written informed consent. The study was approved by the local ethics committee.

\section{Induced Sputum}

Sputum was induced by inhalation of hypertonic saline solution as described by D'Ippolito et al. [5]. All subjects inhaled 5\% saline solution four times for 5 min using a jet nebulizer (PARI MASTER, PARI GmbH, Germany), with a mean volume output of $0.5 \mathrm{~mL} / \mathrm{min}$ and producing particles with a mass median diameter of $3.6 \mu \mathrm{m}$. Sputum was poured onto a petri dish. All viscid portions of the expectorated sample were separated from the whole sputum and placed in pre-weighed polypropylene centrifuge tubes. The specimen was treated with DDT in order to break up the mucus and disperse the cells. The volume added was four times the weight of the plugs and was mixed mechanically with the sputum by aspiration in and out of a pipette about 20 times to ensure mixing. The samples were rocked for $15 \mathrm{~min}$ on a bench rocker at $22^{\circ} \mathrm{C}$. The samples were then filtered through a $40-\mu \mathrm{m}$ nylon cell strainer (Becton Dickinson, USA). A total cell count was performed on the filtered sample, and the viability was checked using the trypan blue exclusion method. The suspension was then centrifuged at $500 \mathrm{~g}$, and the pellet was diluted with PBS to achieve a concentration of 106 cells $/ \mathrm{mL}$. Slide preparations for differential percentage counting of cells were made in a cytocentrifuge (MPW 341, Warsaw, Poland) using $60 \mu \mathrm{L}$ of the cell suspension. Two slides were stained with May-Grünwald-Giemsa. Four hundred non-squamous cells were counted, and the results were expressed as a percentage of the total non-squamous cell count. Countable cytospins were defined by low salivary contamination ( $<20 \%$ squamous epithelial cells) and cell viability $>70 \%$. Additionally, $300 \mu \mathrm{L}$ of sputum suspension was processed for flow cytometric analysis. 
Table 3. Patient characteristics

\begin{tabular}{lccc}
\hline & UC patients $(n=15)$ & Controls $(n=15)$ & $p$ value \\
\hline WBC & $10.5 \pm 2.4$ & $8.9 \pm 1.9$ & 0.053 \\
ESR & $30 \pm 15$ & $6 \pm 4$ & 0.001 \\
CRP, mg/L & $9 \pm 5$ & $5 \pm 2$ & 0.008 \\
ANCA positive & $2^{\mathrm{a}}$ & 0 & \\
SPT & $2^{\mathrm{b}}$ & $1^{\mathrm{c}}$ & \\
\hline
\end{tabular}

${ }^{a}$ p-ANCA pattern. ${ }^{\mathrm{b}} 1$ for Dermatophagoides, 1 for grasses and Aspergillus. ${ }^{\mathrm{c}}$ Cladospo-
rium and Alternaria. WBC, white blood cells; ESR, erythrocyte sedimentation rate; CRP,
c-reactive protein; ANCA, antineutrophil cytoplasmic antibodies; SPT, skin prick test.

\section{Nasal Cytology}

Nasal cytology was performed by anterior rhinoscopy using a nasal speculum and good lighting. The collection technique consisted of collecting scrapings from the middle portion of the inferior turbinate using a Rhino-Probe. Briefly, the cellular material was placed on a glass slide, fixed by air drying, and then stained by May-Grünwald-Giemsa. For the rhinocytogram analysis, $50 \mathrm{mi}$ croscopic fields were read at a magnification of 1,000 to assess the presence of normal and abnormal cellular elements, along with any microscopic features (spots, special inclusions, etc.) important for the diagnosis. Cell counts, bacterial analysis, and fungal analysis were carried out by semiquantitative grading, as proposed by Meltzer and Jalowayski [6].

\section{Skin Prick Test}

Allergy was assessed by the presence of sensitization to the most common classes of aeroallergens by carrying out a skin prick test as stated by the European Academy of Allergy and Clinical Immunology: sensitization was considered when the wheal diameter was equal to or greater than $3 \mathrm{~mm}$. The concentration of allergen extracts was $100 \mathrm{IR} / \mathrm{mL}$ (Stallergenes, Milan, Italy).

\section{Statistical Analysis}

For the statistical analysis, all comparisons were performed by means of the nonparametric Mann-Whitney test for unpaired data sets, the Kruskal-Wallis ANOVA, or the Wilcoxon test for paired datasets, as appropriate. The commercially available Statistica software package (StatSoft, Inc., 2001; STATISTICA data analysis software system, version 6, www.statsoft.com) was used. Differences were considered significant when they were below the $p<0.05$ level.

\section{Results}

Induced sputum analysis showed no differences in macrophage, neutrophil, and eosinophil counts between UC patients and controls ( $68 \pm 20$ vs. $88 \pm 18 \%, p=0.146$; $27 \pm 20$ vs. $22 \pm 18 \%, p=0.478 ; 0.8 \pm 1$ vs. $0.4 \pm 0.4 \%, p=$ 0.161 , respectively). Lymphocyte and NK counts were significantly higher in UC patients when compared to those of controls $(2.8 \pm 0.9$ vs. $0.2 \pm 0.4 \%, p<0.01 ; 6.5 \pm$
4 vs. $2 \pm 1 \%, p<0.05)$. No difference was found in CD3, CD4, CD8, and CD19 counts between UC patients and controls. Nasal cytology results showed a significant increase in lymphocyte counts in UC subjects (12.5 \pm 5.30 vs. $3.5 \pm 4.0)$. We found no difference in neutrophils ( 81.5 \pm 25 vs. $79 \pm 17)$, mast cells $(0.0 \pm 0.0$ vs. $0.5 \pm 0.5)$, eosinophils ( $3.0 \pm 1.5$ vs. $0.00 \pm 0.00)$, and muciparous cells $(77.0 \pm 25$ vs. $76.0 \pm 18.5)$ (Table 2). Five patients (33\%) in the UC group presented a reduction in carbon monoxide diffusion capacity of the lung. The mean DLCO value was $73.85 \pm 14.90$ in the study group versus $87.40 \pm 11.20$ in controls $(p=0.003)$; DLCO/VA value was $73.85 \pm$ 14.30 versus $87.35 \pm 13.50(p=0.04)$. Nonsignificant differences in the mean FVC, $\mathrm{FEV}_{1}$, TLC, and $\mathrm{FEV}_{1} \backslash \mathrm{FVC}$ values were found in patients with or without UC (Table 3). We found a positive correlation between lymphocyte counts in induced sputum and in nasal cytology samples $(r=0.775 ; p<0.001)$. All the patients with DLCO reduction showed an increase in lymphocytes in induced sputum and in nasal tissues. We found a negative correlation between lymphocytes in induced sputum and nasal cytology and reduction in DLCO $(r=-0.889, p<0.001 ; r=$ $-0.841, p<0.001)$. On the other hand, we demonstrated a positive correlation between lymphocytes in induced sputum, nasal cytology, and grade of intestinal inflammation $(r=0.603, p=0.015 ; r=0.600, p=0.013)$.

\section{Discussion}

Structurally, the respiratory and gastrointestinal tracts have many similarities. Both have an extensive, highly vascularized luminal surface area, which is protected by a tight epithelial barrier and an overlying mucus-gel layer from commensal bacteria and pathogens. These epithelial surfaces cover a submucosal layer of goblet cells, glands, and loose connective tissue and mucosa-associat- 
ed lymphoid tissue, composed of resident lymphocytes. This lymphoid tissue regulates antigen sampling, lymphocyte trafficking, and mucosal host defense. Respiratory and gastrointestinal epithelia share a common embryonic origin in the primitive foregut, which may account for their similarities. However, it is most likely that it is the similar inflammatory and immune components of these organs that are the cause of the overlap in pathological changes in respiratory and intestinal mucosal diseases $[7,8]$. In the era of genome-wide association studies, progress has been enormous, culminating in the identification of 163 independent loci associated with IBD. We have learned that Crohn's disease and UC share several disease susceptibility loci, many of which are implicated in other immune-mediated diseases $[9,10]$. Furthermore, the discoveries of genes related to T-helper-17 cell differentiation and function, and genes influencing innate immunity and microbial immune response, have brought major insights into disease pathogenesis, pointing to altered bacterial handling as a key factor in disease pathogenesis $[11,12]$. A number of clinical observations and experiments in animal models have demonstrated a key role played by regulatory T cells, CD4+CD25+ (Tregs), in the pathogenesis of IBD and in the appearance of its systemic manifestations [13].

Bronchus-associated lymphoid tissue, gut-associated lymphoid tissue, and nasal-associated lymphoid tissue are all parts of the mucosa-associated lymphoid tissue. Lymphocytes become activated according to the inflammatory stimuli they receive, and mis-homing of lymphocytes may provide an explanation for the migration of inflammation.

To the best of our knowledge, this is the first study considering the role of nasal mucosa as a possible target organ in UC. In contrast, pulmonary involvement is rare but well defined in the literature. Bonniere et al. [14] studied, by using BAL, 22 consecutive patients with Crohn's disease, free from respiratory symptoms and showing a normal chest X-ray. They demonstrated a high proportion of subclinical lymphocytic alveolitis. In another sim- ilar study involving patients with UC, Karadag et al. [15] demonstrated a subclinical alveolitis with accumulation of lymphocytes in the septal area with minimal septal fibrosis in $50 \%$ of the study population.

We assessed pulmonary involvement by using a noninvasive method such as induced sputum because all patients were free of pulmonary symptoms, and the method is validated and shows a good correlation with BAL data. In an interesting paper, Fireman et al. [16] performed induced sputum in 19 UC patients. They showed a significantly higher percentage of eosinophils in UC patients than in the control group (5.4 \pm 9.6 vs. $0.49 \pm 1.0 \%, p=$ $0.001)$ and a lower $\mathrm{FEV}_{1} / \mathrm{FVC}$ ratio $(77.6 \pm 6.03$ vs. $85.6 \pm$ $7.7 \%, p=0.001$ ), although they found no differences in the percentage of lymphocytes. These results warrant some comments. The study population included asthmatics, smokers, and patients with active disease or in remission and, above all, the vast majority of patients were taking 5-ASA, which could be the cause of the pulmonary eosinophilia [16].

Our study has an important strength. The study group is well selected: free from asthma, all patients were nonsmokers and taking no drugs. The major weakness is the few patients recruited. In conclusion, our study demonstrated that UC patients may have an increased number of lymphocytes in the lung and nasal mucosa. The nasal and lung lymphocytosis correlates with the grade of intestinal inflammation calculated by using our personalized scoring system. The lung and nasal involvement is subclinical.

\section{Statement of Ethics}

All patients gave written informed consent. The study was approved by the local ethics committee.

\section{Disclosure Statement}

The authors declare no conflicts of interest.

\section{References}

1 Ott C, Scholmerich J. Extraintestinal manifestations and complications in inflammatory bowel disease. Nat Rev Gastroenterol Hepatol. 2013;10:585-95.

2 Papanikolaou I, Kagouridis K, Papiris SA. Patterns of airway involvement in inflammatory bowel diseases. World J Gastrointest Pathophysiol. 2014 Nov;5(4):560-9.
3 Rodriguez Rosin R. Bartolome Sd, Huchon G, Krowka MJ. Inflammatory bowel disease, chronic liver disease and the lung. Eur Respir J. 2016;47:638-50.

4 Ji XQ, Wang LX, Lu DG. Pulmonary manifestations of inflammatory bowel disease. World J Gastroenterol. 2014;20:13501-11. 
5 D’Ippolito R, Foresi A, Chetta A, Casalini A, Castagnaro A, Leone C, et al. Induced sputum in patients with newly diagnosed sarcoidosis: comparison with bronchial wash and BAL. Chest. 1999 Jun;115(6):1611-5.

6 Gelardi M, Russo C, Fiorella ML, Fiorella R, Canonica GW, Passalacqua G. When allergic rhinitis is not only allergic. Am J Rhinol Allergy. 2009 May-Jun;23(3):312-5.

7 Keely S, Talley NJ, Hansbro PM. Pulmonaryintestinal cross-talk in mucosal inflammatory disease. Mucosal Immunol. 2012 Jan;5(1):718.

8 Tulic MK, Piche T, Verhasselt V. Lung-gut cross-talk: evidence, mechanisms and implications for the mucosal inflammatory diseases. Clin Exp Allergy. 2016 Apr;46(4):519-28.
9 Ye BD, McGovern DP. Genetic variation in IBD: progress, clues to pathogenesis and possible clinical utility. Expert Rev Clin Immunol. 2016 Oct;12(10):1091-107.

10 Torres J, Colombel JF. Genetics and phenotypes in inflammatory bowel disease. Lancet. 2016 Jan;387(10014):98-100.

11 Elshal MF, Aldahlani AM, Saadah OL, Mc Coy GP. Reduced dendritic cells expressing CD200R1 in children with inflammatory bowel disease: correlation with Th17 and regulatory T cells. Int J Mol Sci. 2015;16:289989010.

12 Morgan ME, Koelink PJ, Zheng B, den Brok $\mathrm{MH}$, van de Kant HJ, Verspaget HW, et al. Toll-like receptor 6 stimulation promotes Thelper 1 and 17 responses in gastrointestinalassociated lymphoid tissue and modulates murine experimental colitis. Mucosal Immunol. 2014 Sep;7(5):1266-77.
13 Pedros C, Duguet F, Saoudi A, Chabod M. Disrupted regulatory $\mathrm{T}$ cell homeostasis in inflammatory bowel diseases. World J Gastroenterol. 2016 Jan;22(3):974-95.

14 Bonniere P, Wallaert B, Cortot A, Marchandise X, Riou Y, Tonnel AB, et al. Latent pulmonary involvement in Crohn's disease: biological, functional, bronchoalveolar lavage and scintigraphic studies. Gut. 1986 Aug; 27(8):919-25.

15 Karadag F, Ozhan MH, Akçiçek E, Günel O, Alper H, Veral A. Is it possible to detect ulcerative colitis-related respiratory syndrome early? Respirology. 2001 Dec;6(4):341-6.

16 Fireman E, Masarwy F, Groisman G, Shtark M, Kopelman Y, Kivity S, et al. Induced sputum eosinophilia in ulcerative colitis patients: the lung as a mirror image of intestine? Respir Med. 2009 Jul;103(7):1025-32. 